\title{
Exploration of Climate Change in Architectural Design Studio
}

\author{
Eray Bozkurt ${ }^{1,}$ \\ ${ }^{1}$ Izmir Yasar University, Department of Architecture, Selcuk Yasar Campus, 35310 Bornova-Izmir, \\ Turkey
}

\begin{abstract}
Many researches reveal that climate change is a significant public issue. With the rising awareness of climate change impacts by both national and international bodies, building climate resilience has become a major goal for many institutions. This influence began to find path in architectural design education. Architectural design education is mostly given in the design studios. Each semester, the studio instructors prepare design briefs that need to be completed in a required period of time with given constraints. This is an opportunity for the design studios to adapt new theories and approaches like climate change into the design study. This article describes the experiences of the studio team after the design work proposed for climate. The study explains the transition from research to design stage. The studio tutors collected data after close observations on 42 students from Yasar University, School of Architecture third year studio.
\end{abstract}

\section{Introduction}

Conventional building systems of the Modern era have aimed to resist the outdoor environment, instead of being responsive to local climate conditions. Vernacular and traditional architecture styles before the Modern era used the local climate opportunities like the orientation towards the sun, the ratio of the building surface and the cultural traditions, etc., to sustain thermal comfort inside the spaces. The conventional building systems have ignored the relationship between human and nature. These systems have triggered today's energy-hungry construction methods.

Climate change is a recent topic that needs to be addressed much more in architectural design education to prepare students for the unforeseen challenges. It will become necessary that more schools will address this issue in their future curriculum and that more tutors acquire sufficient basic climate design knowledge to be able to guide such studios.

Climate resilience efforts cover social, economic, technological, and political strategies that are being implemented at all scales of society. From local community action to global treaties, addressing climate resilience is becoming a priority in urban environments. The key focus of climate resilience efforts is to address the vulnerability of human existence

\footnotetext{
* Corresponding author: eray.bozkurt@yasar.edu.tr
} 
that communities currently have, concerning the environmental consequences of climate change. The possible relations between climate resilience and the built environment need to be explored for further adjustments.

\section{Climate change and architectural design education}

Current debates about climate change circle around the necessary speed of action to tackle with the problem. Some experts defend the fact that the idea of climate change is a hoax because of the lack of evidence. However, the catastrophic events acquiring around the world reveal that the transformation of climate has already began especially locations near the sea. The melting down the ice caps, have been changing the sea levels, which is a strong proof for the upcoming disasters of the future. As seen in Figure 1, Izmir bay area effected from excessive rain and storm, caused serious damages to the facilities near the sea.

Many disciplines still is not prepared enough for the climate change conditions; lack of knowledge and awareness about the topic. Many people have been ignoring the possible disasters, even the professionals in the built environment. The forefront role of the climate change has not developed mutual strategies to tackle the problem. Especially, architectural schools need to educate future architects to correct this situation.
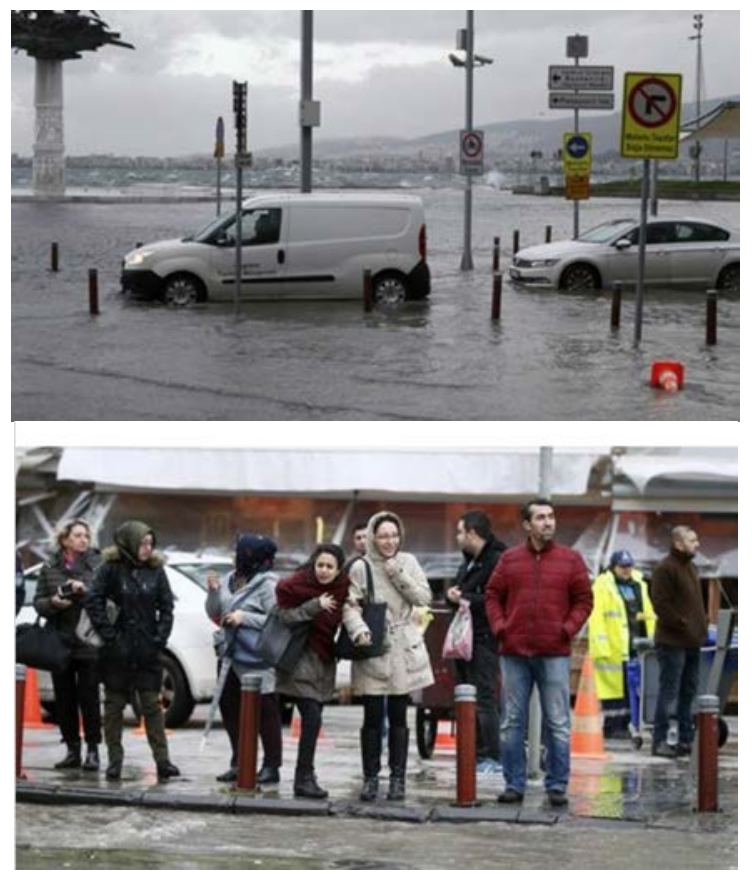

Fig. 1. After heavy rain and storm, Izmir Kordon was underwater in February 2018.

Different disciplines are not yet ready for the transformations that climate change will create on the Earth Systems. Many communities are not paying enough attention to the problems about the changes that may occur in the near future.

Design studios are interdisciplinary zones to imply new theories and approaches. Altomente et al. mentioned the barriers for design education and discussed the insufficient training of experts and architects. Lack of knowledge transfer between professional domains reduce the quality of the architectural design education. Altomente et al. states that conventional teaching and learning approaches may not be appropriate for addressing education for sustainability. It will become necessary that more schools will address this 
issue in their future curricula and that more tutors acquire sufficient basic climate knowledge to be able to guide such studios [1].

\subsection{The description of the studio}

A studio is a workspace where students explore a set of skills with or without the presence of an instructor. Studios engage students with architectural knowledge using various projects.

Third year architectural design studio prepares students to organize their own architectural design building proposals. This is almost valid for all architectural schools around the world. The current case study took place in Yasar University, school of architecture. It's a young university that tries to evolve to sustainable education. For this purpose, the department wanted to change the conventional system. The studio coordinator suggested an atelier system, but the resources were not enough to run the system. Unit system suggested instead. Four units created to study the climate change topic in four different approaches. First unit titled 'Sustainable Heritage' asked to design an accommodation in a historical context. They concentrated more on preserving the historical buildings with adaptive reuse strategy. Second unit concentrated on the low carbon strategies. Students developed projects related with the topic. Third unit decided to build an expo center on a large-scale site. Forth group worked on energy efficiency subject. The case study will focus on second unit and 42 students' experiences.

\subsection{The advantages of design brief}

The brief describes the requirements of the design studio, is an opportunity to communicate with the students to describe the challenges and the limits of the proposed project. The theme of the project can be explained in the brief to guide the students for one semester period, let them focus on particular subjects, tools and methods. Second unit designed areas in Urla, related to their researches and site investigations. The design brief guided them through the beginning till end of the project. All the requirements and constraints described in the brief document. The requirements were given in the project brief before the course period starts. The aim of the brief is not to give all the clues, researches, notes and discussions done on the particular theme. The design tutors persuade students research and collect data for them to discover their own innovative ideas. The design tutors instructed not to give any design suggestions. However, their role is to evaluate whether their project worth doing for 14 weeks of studio period.

\subsection{Adaptation of climate change}

Another problem of the adaptation of the climate change is the level of knowledge of the students and tutors. The tutors hold strong backgrounds on building design, structure studies, energy efficiency and sustainable topics. These make them eligible for the current positions. Students before they attend the studio, they practiced how to present architectural idea and learned how to use visual presentations. Another advantage of the students is they studied 'Environmental Control Systems and Energy Efficiency' theory course before they enter the third-year level. They took also, 'Sustainable Buildings and the Cities' course parallel to their studio. Some theoretical backgrounds were discussed during the course hours and even some exercises introduced related with the sustainable topics. They used the outcomes of their designs in 'Computational Design' course, submitted all the technical issues about their projects. 


\section{Methodology}

The purpose of third year studio is to provide students with experience designing in a sustainable approach. This study collects students' opinions about their learning experiences in the proposed unit system. It addresses the design studio learning experiences of third year architectural students in Unit 2. The basic structure of the unit persuaded students to form a group of three. In total, 14 groups conducted a site analysis in Urla / Izmir. To boost their creativity, the groups were free to find their own site and develop their own program considering climate change design brief and low carbon issue.

First four weeks, students conducted an intensive research on climate change and low carbon emissions. Before they visit the site in Urla, they excavated all historical and technical information about the surrounding. They checked whether there is any initiative about climate change ideas. There were three institutions; one is an underwater archaeological team from Ankara University, second is shipping technologies group from Dokuz Eylül University, and third group is aqua cultural engineering from Ege University. All the activities of these institutions provided necessary conditions for innovative design solutions.

After the completion of the research period, students prepared two design options for a chosen area. Most of the ideas emerged with the influences of the research and site investigations. Most of the fourteen group designed a research centre, under different themes.

Students got support from the desk critics given by their tutors. They can access the studio space 7 days and 24 hours. Lectures planned about the climate change, delivering expert opinions about the research field.

\section{Results}

Students' capability with the design process developed technical solutions by employing the fundamental processes associated with sustainable and innovative solutions. All units discussed the adaptation of climate change as a concept idea, learning experiences, and their design findings. Although students had personal views on the sustainable design and other subjects, they limited themselves to couple of influential ideas. Among all 42 students, they considered the ideas mostly related with sea level rising, renewable energy sources, food production and floating structures.

The findings show that the students described their learning experiences as innovative, improved their knowledge and design abilities. They claimed that they observed new viewpoints in their conceptual thinking.

\section{Conclusions}

Climate change is a significant issue, especially in the built environment. The concept idea of protecting the planet is out there since 1970 s oil crisis. Since then, many efforts were given on energy and environment issues. Architecture Schools had contributed many attempts to transform the conventional building systems into more sustainable and environmentally friendly design solutions. However, the expected rapid development never happened due to lack of interest towards climate change.

The study proved that it is possible to adapt the climate change theme in a design studio. The consequences are the level of knowledge and expertise, finding the right tools for further investigations, and supporting long lasting design solutions. 


\section{References}

1. Altomonte, S., Rutherford, P. \& Wilson, R. Mapping the way forward: Education for sustainability in architecture and urban design. Corp. Soc. Responsib. Environ. Manag. 21, 143-154 (2014).

2. Tasc1, B. G. "Sustainability" Education by Sustainable School Design. Procedia - Soc. Behav. Sci. 186, 868-873 (2015).

3. Stieldorf, K. Building physics, design, and the collaborative build: Sustainability and resilience in architectural education. Archit. Des. 88, 102-109 (2018).

4. van den Branden, K. Sustainable education: Basic principles and strategic recommendations. Sch. Eff. Sch. Improv. 23, 285-304 (2012).

5. Lenzholzer, S. \& Brown, R. D. Climate-responsive landscape architecture design education. J. Clean. Prod. 61, 89-99 (2013).

6. Stubbs, E. A., Zimmerman, A. R., Warner, L. A. \& Myers, B. E. Reflecting on a multidisciplinary collaboration to design a general education climate change course. $J$. Environ. Stud. Sci. 8, 32-38 (2018).

7. Jacobson, M. J. et al. Designs for learning about climate change as a complex system. Learn. Instr. 52, 1-14 (2017).

8. Anthony, K. H. Journal of Architectural Education Designing for Diversity: Implications for Architectural Education in the Twenty-first Century Designing for Diversity: Implications for Architectural Education in the Twenty-rst Century. $J$. Archit. Educ. 257-267 (2016). doi:10.1162/104648802753657969

9. Birks, F. \& Prater, K. Adapting to global change: Ageing, urbanisation and resilience. Archit. Des. 84, 28-35 (2014).

10. Carmody, J. The role of architectural research centers in addressing climate change. Enquiry 6, 33-39 (2009).

11. Loftness, V., Lam, K. P. \& Hartkopf, V. Education and environmental performancebased design: A Carnegie Mellon perspective. Building Research and Information 33, 196-203 (2005).

12. Stupar, A., Mihajlov, V. \& Simic, I. Towards the conceptual changes in architectural education: Adjusting to climate change. Sustain. 9, (2017).

13. Stevenson, F., Roberts, A. \& Altomonte, S. Designs on the planet: A workshop series on architectural education and the challenges of climate change. in PLEA 2009 Architecture Energy and the Occupant's Perspective: Proceedings of the 26th International Conference on Passive and Low Energy Architecture (2009).

14. McMahon, M. J., Dascalu, S. M., Harris, F. C., Strachan, S. \& Biondi, F. Architecting climate change data infrastructure for Nevada. in Lecture Notes in Business Information Processing 83 LNBIP, 354-365 (2011).

15. Zari, M. P. Biomimetic design for climate change adaptation and mitigation. Archit. Sci. Rev. 53, 172-183 (2010).

16. Pedersen Zari, M. Bioinspired architectural design to adapt to climate change. World Sustainable Building Conference SB08 (2008). 